\title{
The Origin of Species by Large, rather than by Gradual, Change, and by Guppy's Method of Differentiation.
}

\author{
BY \\ J. C. WILLIS, M.A., Sc.D., F.R.S., \\ European Correspondent of the Botanic Garden, Rio de Janeiro.
}

'May not the births of new species, like the deaths of old ones, be sudden.'-LyelL.

$\mathrm{T}$ the days of Special Creation it was of course assumed that each species 1 was created de novo in the form in which it was found to occur most widely upon the surface of the earth, while varieties were supposed to owe their origin to subsequent change. Towards the end of this period, however, it began to be recognized, e. g. by Lyell and Hooker $(8$, p. 702 , and 6, p. xxv, quoted in 'Age and Area', p. 3), that all existing species were not created simultaneously, but that new ones; which would usually (of necessity) occupy less area, were from time to time appearing. Once this was fully recognized, it is clear that the way was open for the acceptance of some scheme of evolution, so soon as something feasible should be proposed.

The great difficulty that lay before the 'special creationists' was to explain why species were so obviously grouped by affinities (as they were called), a fact which was perceived at a very early date, and was the underlying motive of the attempts that were continually being made to group plants and animals into genera and families in what was called the 'natural' system ${ }^{1}$ of classification. If species were specially created, each for its own place, there seemed no reason why they should be so evidently capable of arrangement into genera and other groups, and why these groups should usually occupy continuous areas. Nothing, evidently; could explain affinity but some scheme of evolution. If we imagine species showing affinity to have descended from some common ancestor, and therefore suppose that on the whole the affinities of species will be more and more pronounced the less

1 'A genus is called natural not because it exists in nature, but because it comprehends species more naturally resembling each other than they resemble anything else' (Lindley (7), p. xvi).

Annals of Botany, Vol. XXXVII. No. CXLVIII. October, 1923.] 
' ancestral' their common ancestor may be, we obtain a simple and satisfying explanation. The present existing complex assortment of species must be conceived as having been evolved from a preceding and probably simpler one.

So obvious an explanation was evolution that it had already been put forward in very early times, but no one had been able to suggest any way in which it might be supposed to produce its results; and without a feasible mechanism no one was ready to accept it as an explanation, for it was not realized that its acceptance would make any difference to the progress of science.

At this stage Charles Darwin came upon the scene as the man of the moment, putting forward the simple mechanism of Natural Selection, a principle which when once stated was seen to be of axiomatic nature, and a principle which caught, and has held, the public fancy. ${ }^{1}$ It seemed clear that results might be produced by aid of this mechanism, and upon this ground evolution was rapidly accepted, for at that time the laws of heredity were not understood, and it was supposed that all change, due to whatever kind of variation, fluctuating or not, was fully inherited, a supposition that later work has shown to be ill-founded.

Evolution, once adopted, was found to explain so enormous a range of facts, and its acceptance pointed the way to so many new lines of research, that it rapidly attained an unassailable position, quite independent of any support that might be given to it by the theory of Natural Selection. For a long period, however, Evolution and Natural Selection were not sharply distinguished from one another, and anything that gave evidence in support of the former was also supposed to uphold the latter, though the inherent logical weakness of this position was often pointed out. For a long time the current of opinion in favour of 'Darwinism' was too strong to take account of any obstacles. I have lately looked over some anti-Darwinian books in the Cambridge University Library, and have been struck with the frequency of such observations as the following:

'It follows, therefore, that if we accept the Evolutionists' view, every specialised chemical compound met with in some living beings only must fulfil the condition, that every approximation to the complete compound ${ }^{2}$ must have been of advantage to the being in which it was produced in the struggle for life .... unless these very substances existed in, and formed points of difference between, Mr. Darwin's few original forms' (9, p. I34).

Small steps in the production of chlorophyll, for example, could not be of any advantage (9, p. 168). On p. 188 Maclaren asks why a plant should

1 Because, it has been suggested to me by Mrs. Arber, each man is pleased to think that he is one of those picked out by selection.

${ }^{2}$ A thing which does not occur in nature, it is pointed out. 
elaborate so deadly a poison as aconite, when a simpler one would do; and on p. 194 he points out that change of climate does not change the chemistry of a plant, so that there is no opening for Natural Selection in a change of conditions.

Coe (2, Ch. II) gives a very good series of extracts from Darwin, Wallace, and others, showing how they contradict themselves, e.g. in the ' Origin of Species', pp. 65, 146, Natural Selection is said to be always acting, while on pp. 85 , I69, it only acts at long intervals and under certain favourable circumstances. On p. 25 he points out that it only comes into operation in case of adverse changes; it is not wanted if the change is favourable. Also the changes that bring it into operation must not be too rapid, or the organisms would perish, nor too mild, or they would not involve a question of life and death. Just the right amount is wanted. Natural Selection must wait for favourable variations to turn up, and they may not turn up in time. Geometrical increase of a species does not occur. As the numbers keep roughly constant, though four give say eight, these do not give sixteen; the number is again reduced to four every time; the eight do not survive to propagate.

The great bulk of the research carried on was based upon Natural Selection, inasmuch as it seemed to give a satisfactory explanation of the facts of adaptation. The idea of adaptation was pushed to absurd extremes, and adaptations were found-as indeed was necessary if Natural Selection, which was essentially a theory of adaptation, were to hold its place as an active factor in evolution-in almost everything that was conceivable with the greatest stretches of imagination. In spite of desperate effort, however, in which one might say that the imagination was stretched beyond the limits of perfect elasticity, no one ever succeeded in finding adaptation in the enormous bulk of the characters that divide one species or genus from another, whether in plants or in animals. And not only so, but a more thoughtful analysis of the cases of adaptation actually described showed that nearly all of them involved correlated adaptation. For example, the possession of tendrils as climbing organs was always accompanied by flexibility of the stem, which was no longer able to stand by itself. It was therefore necessary to suppose that selection, picking out the very doubtfully advantageous beginning of tendrils, picked out also the less doubtfully disadvantageous weak stems. This difficulty has always been a fatal weakness in the explanation of adaptation by selection.

This same correlation difficulty repeats itself over and over again in other cases, and is a very formidable one to whose explanation the theory of Natural Selection has been unable to give any clue. Climbing plants occur over and over again among closely related erect plants, whether in the same genus or in closely allied genera, so that it is clear that the climbing habit has been independently acquired in hundreds of cases, and therefore 
that it must be easy of acquisition. It is obviously inconceivable that all can be descended from a common climbing ancestor. Now in the case of herbaceous climbers, such as are common in the north, it may be just possible to conceive that weakness of the stem was gradually acquired, for there is but little woody tissue in any case; but how is this supposition to be applied to tropical lianas with large woody but flexible stems? Is it conceivable that the stems of the trees and large shrubs which make up much of the genus Bauhinia, for instance, were gradually selected for weakness till the lianas were produced? Some of the climbing Bauhinias have tendrils, and some twine. Did the latter wait till the utterly useless and dangerously disadvantageous weak stems had been selected down to the point where they became flexible, before they began to evolve the twining habit by selection? Yet they could not begin to select the twining habit till the weak stems had been arrived at, and a weak stem, with no means of support, in a tropical forest would stand a very poor chance. And why do some species twine and some climb by tendrils? One has only properly to realize the enormous difference between the stem of a tree and that of a woody climber, and the entire lack of use-value in any small change in strength or rigidity, together with the hopeless position of a weak stem with no means of support, to realize at the same time the total absurdity of the 'explanation' provided by Natural Selection. It is difficult to have long experience, in the tropics at any rate, without being convinced of its utter and pathetic inadequacy as an explanation of the facts, as I was convinced about I899, after three years in Ceylon, and have tried to make clear on numerous subsequent occasions.

Though previous to about I 890 criticism had little or no effect, the reverence in which Natural Selection was held has since diminished, more especially with the rise of biometrical measurements and statistics, which showed that the universally occurring fluctuating variations upon which Darwin mainly depended were not fully hereditary, but exhibited regression to such an extent that improvement by their means was not possible beyond a certain point. Another strong bar to its acceptance was the growth of Mendelism, which was quite incapable of explanation upon this theory.

At the same time de Vries was elaborating the theory of Mutation (3), according to which progress in evolution took place by fixed and hereditary changes that at times appear suddenly, in the form commonly known as sports; and it is with de Vries that the credit of the change from the Darwinian view of very gradual alteration really lies. Much subsequent work has shown reason to believe that his mutations in Oenothera do not rest upon sufficient evidence, regarded as mutations. This, however, is but a locking of the stable door after the emergence of the theory of Mutation, which has come out to stay. It is steadily gaining ground, and at the present time the older theory of progress by means of fluctuating variations 
has probably very few adherents. Even its most strenuous supporters now usually begin with a mutation, though they may improve it afterwards by Natural Selection of fluctuating variation.

Though by education an enthusiastic adherent of this latter theory, I found so many difficulties that were insoluble, and so often found simpler explanations, that I soon became a convert to Mutation (10, 2nd ed., p. I I 8 ; 3rd ed., p. 208). It struck me at once, however, that there was a logical unsoundness in the new theory, for there was not the least evidence to suggest that a sudden change or mutation in one direction could be followed by another in the same direction, if the first were selected; yet this was necessary if new structures of marked difference were to rise by small mutations, whether with or without Natural Selection.

This supposition was largely based upon my investigation of the flora of Ritigala Mountain (12) in Ceylon in 1905, and in May I907 (i. e. a year later than Guppy, who will be mentioned presently) I published a paper (13) dealing with" some of the implications of the subject. This paper was chiefly concerned, however, with bringing up a trenchant argument against the natural selection of fluctuating or infinitesimal variations, an argument which has been used in the controversy on several occasions, and has never been refuted.

It was shown that in the enormous majority of cases no use could even be suggested for the characters that mark specific or generic distinction, in spite of the great amount of work on adaptation. Also that, even if some use-value might conceivably be found in rare cases for the mature character, it could not be supposed to exist for the early stages of the same. The case of the weak stems that always accompany tendrils, and of the tendrils themselves, which was mentioned above, affords an excellent illustration of the practical impossibility of intermediate stages. This case occurs in hundreds of different places in the system of the flowering plants, so that all cannot be supposed to have a common ancestor that acquired the climbing habit, and combination of tendrils with weak stem, once for all.

The case was considered of Coleus elongatus, Trimen. This is a species peculiar to the summit of Ritigala, where it is accompanied by other peculiar species within a very limited area of not more than five acres. It was shown that there was not the least reason to suppose it (or them) to be of the nature of survivals. Consequently, even if the characters were ever useful or the reverse, they must have been so upon Ritigala summit, and nowhere else. This fact rendered unavailable the refuge to which the supporters of adaptation fly in such cases of difficulty-that the characters must have been useful somewhere else. Their other refuge-that they must have been useful at some time-was also rendered very precarious by the fact that geological and other evidence seemed to show that the conditions upon Ritigala had remained little altered since the Tertiary. 
It was, moreover, shown that no use-value could conceivably be put to the two most important characters by which this Coleus was distinguished from other species of the genus - the equally toothed calyx and the different type of inflorescence. Even in the minor characters of difference (cf. 'Age and Area', p. 152, or below, p. 620) it was very difficult, if not usually impossible, to point out any way in which they could be of service or disservice. It was then shown that in the case of the two chief, and of some of the minor characters, evolution from the characters of the other Colei, or from some intermediate type, by gradual variation, was impossible, on account of the impassable gaps in the transition, only to be passed by sudden and rather 'large' variation. In the case of the calyx, for example, all sepals behave alike in ordinary variation, and a calyx of one large and four small sepals could never vary gradually in the direction of one with five equal sepals.

Further than this, evolution by Natural Selection demands variation in the same direction in large numbers, to avoid intercrossing, and on the summit of Ritigala there is not sufficient room for four local species to have evolved in this way - a Coleus on rocky spots, a Trichomanes in shady places, a Bulbophyllum living epiphytically, and a Cyperus in open grassy places, to say nothing of the endemic varieties. Finally, the Coleus was accompanied at the summit by its most nearly related species, $C$. barbatus (common in tropical Asia and Africa), living in similar spots, and just as common. This latter species is, upon my view, the probable ancestor of the former.

Many similar cases were then brought up from the floras of Ceylon and other countries to show that endemic species as a general rule were separated from the 'wides' that accompanied them (and were usually closely related) by differences which could only be passed over by mutations, often 'large'. To make a few quotations: 'Ranunculus sagittifolius, confined to the high mountain region about Nuwara Eliya, differs widely from the only other Ceylon buttercup, $R$. Wallichianus (South Indian also), which occurs side by side with it, though in drier and sunnier places, but is closely allied to $R$. reniformis of the mountains of the Western Indian Peninsula, differing mainly in the petals, which are five in the Ceylon species, I 2 to I 5 in the Indian one.... Are we to suppose the conditions of life so different in the Ceylon and Indian mountains that a five-petalled flower will suit the one, a twelve-petalled the other? Or how is the one to pass into the other, or both to arise from a common ancestor, except by discontinuous variation?' 'Can it be supposed that the simple obovate-lanceolate leaf of Acrotrema intermedium fits it for the Kitulgala district, while the pinnate leaf with linear-lanceolate segments of $A$. Thwaitesii fits that species for the Dolosbage district, but a few miles away, a trifle higher up, and in a similar climate?...A. lyratum, characterized by very long peduncles, is found only on the summit of Nillowekanda, an isolated precipitous rock ... is it 
to be supposed that the long peduncles are any advantage, or that the struggle for existence upon the summit of Nillowekanda is so keen that they can have evolved there by infinitesimal variation?... What advantage can the two ovules of Polyalthia Moonii and P. persicifolia be against the one of the other species? P. rufescens, another species with two ovules, and closely allied to both, occupies the Cochin district of South India, and why should there be three species in so similar a country, especially as the Ceylon species live in the same district? And how did the one form get to the other, or both arise from a common ancestor, except by mutation?... Similar queries might be asked 800 times for the 800 endemics comprised in the Ceylon flora....'

The characters that differentiate allied species are as a general rule of no importance one way or the other, and cannot have been the subject of selection. Only in rare cases do they even allow of intermediate stages. The only possible explanation to my mind was that provided by the 'parent and child' theory, that parent and child might, and very often did, exist side by side. To quote my paper again (p. I4) : 'The general principle on which India and Ceylon have been peopled with the many species which they contain would seem to be that one very common species has spread widely, and, so to speak, shed local endemic species at different points, or else $^{1}$ that one species has spread, changing at almost every point into a local endemic species, which has again changed on reaching new localities.'

This view of evolution by mutations which in one step-or perhaps but less probably in two or more-transform one species by divergent variation into another, without in any way necessitating the death or destruction of the parent form (so that parent and child might survive together), had been published a year previously by Guppy $(4),{ }^{2}$ whose book I had not then seen. It was clear that if one much-localized species were derived directly from another (usually of wider range) the mutation must almost certainly be large, and as there was no reason to suppose a mutation in any given direction to be followed by another in the same direction, the change from one species to another must probably be due to one or a few mutations, each one in the latter case probably changing completely one or more characters. Correlation being very common, one would incline to expect several or all of the characters of a species to change at once. In Coleus elongatus, for example, it was clear that nothing but a big mutation could alter calyx or inflorescence, though it was not absolutely necessary that both should be altered by the same mutation.

We have now to go back and consider the work of Guppy (4), in this same direction. His views were also derived from the study of local

1 Meaning ' in other cases'.

2 Priority in the idea of large variation is not claimed for either Dr. Guppy or the writer; it dates at least from Geoffroy Saint-Hilaire; cf. also the writings of Owen, Mivart, and others. 
endemic forms, this time in the Pacific Islands. Dr. Guppy noticed that there seemed to be three principal stages in the development of local endemism. In the first stage the island was occupied, so far as a given genus was concerned, by one or more widely-ranging species usually of very variable nature, such, for example, as Metrosideros polymorpha. In the second stage the wide-ranger was accompanied, in some of the islands at any rate, by local endemic species more or less closely allied to it, and in the third stage there were only local endemics. He therefore imagined, just as I had done in the case of India and Ceylon, that the wideranging species had given rise to the local forms, and that it might-or perhaps in any case did-ultimately disappear. The following quotations will suffice to indicate the point of view which Dr. Guppy took up in 1906 :

' One where the extremely variable or polymorphous species plays a conspicuous part, as represented in such genera as Alphitonia, Dodonaea, Metrosideros, Pisonia, and Wikstroemia, the general principle being that each genus is at first represented by a widely ranging, very variable species, which ultimately ceases to wander and settles down, and becomes the parent of different sets of species in the same groups' $\left(4, \mathrm{p} .5^{\text {I } 9)}\right.$.

' The rôle of the polymorphous species belongs alike to the plant and to the bird. A species that covers the range of a genus varies at first in every region, and ultimately gives birth to new species in some parts of its range. Then the wide-ranging species disappears, and the original area is divided up into a number of smaller areas, each with its own group of species' (p. 522).

Dr. Guppy was so kind as to give me a few notes upon his theory of Differentiation, from which I extract the portions shown in quotation marks. The theory of Differentiation involves the idea of variation that was always held, for example, by Hooker and Huxley, and which they pressed upon Darwin,to whom it was always a stumbling-block-that it involved a tendency to divergence (cf. Guppy in 'Age and Area', pp. I04-5).

'The same conception of divergent variation is attributed to Goethe by Geddes in his article on Variation in vol. 24 of the 9th edition of the "Encyclopaedia Britannica", p. 77. The German philosopher held a view which included, besides the centripetal force of heredity, that of a progressive or centrifugal tendency to adaptation to environment.... But there were other eminent investigators who seem to have got into the differentiation stride as soon as they tackled the subjects of variation and distribution. This is indicated in the "loi primordiale" of A. de Candolle in his "Géographie Botanique', ii, p. $133^{8}$, where the secondary modifications of the great plant groups are attributed to variations in conditions produced in the course of geological ages. Huxley, when he handled the gentians, got into the same stride, and in his letters to Hooker in Sept. 1886, where he characterizes 
the primary group of these plants as the least differentiated, he alludes to the strange general parallelism in the northern hemisphere between the gentians and the crayfishes. It is the case of the tapirs over again, he also adds.'

'If we take the history of distribution of such families as the Menispermaceae and the Monimiaceae [cf. 'Age and Area', p. I 72] we have the story of the dissociation of two family types into tribes, genera, species, and varieties, and as the parent type differentiates into tribes, and the tribes into genera, and the genera into species, varieties, and races, a subsidiary principle which has been termed "Rank and Range" comes into view. Here range goes with systematic rank, and since age goes with it as well, we have the Age and Area principle exemplified.

'But the whole story of the distribution of the flowering plants since their appearance in secondary times has been a story of differentiation of types and the dissociation of floras. From the migration standpoint this has long been studied by Mrs. Reid. But what I am concerned with here is the dissociation of the mixed floras of the Eocene ages, the elements of which are now separated in different climatic zones, and the breaking up of the synthetic pro-angiosperm types of the Cretaceous ages, types that combined characters that are now far apart both in a systematic and in a geographical sense. The phrase of "the age of palms and poplars" has been applied to the mixed Eocene floras, but the same forces of differentiation that in recent ages have placed palms and poplars in different climatic zones previously broke up the comprehensive pro-angiosperm types of the Cretaceous period, types that ushered in the appearance of the Dicotyledons, which now present the characters of the primary parent types in a dozen different families systematically and geographically separated from one another. The dissociation of mixed floras, and the differentiation of synthetic or comprehensive types, have worked together to bring about the present system of plant distribution.

'It is noteworthy that Weismann, after supplying the machinery for the building up of types, provided the machinery for breaking them up. Concomitant variation of many individuals in the same direction and under the same stimulus of changing environment furnished the type which under the influence of varying conditions would break down into lesser groups.

'After all, differentiation comes nearer home to us than the Darwinian machinery of evolution. It has influenced in the past, and is still in the present influencing, our amusements, our arts and sciences, and even our creeds. It is a more comfortable doctrine than that involved in the belief in the ruthless struggle of existence that is based on the triumph of the strong and the crushing of the weak.'

To return to my own work, in a later paper (15) I worked at the problem of the distribution of the Dilleniaceae, upon the assumption that mutation was the true explanation of evolution. I showed that there was a general tendency in the larger genera, here as in other families, for there to be one or two widely ranging species, accompanied at various spots by local endemics; and I pointed out that the easiest explanation was to suppose the former to shed the latter. On this supposition, it was clear that 
there was no necessary reason why the whole tree of the descent of a family (descent and formation of its genera) should not actually exist upon the earth at the present time, and it was suggested that all the Dilleniaceae might be descended (directly, or indirectly through other genera) from Tetracera, the most widespread and probably the oldest genus.

In a later paper (16) it was pointed out that the fact that Eugenia, Hedyotis, and other genera were represented in Ceylon by different species upon different hill-tops was one which offered great difficulties to the theory of Natural Selection, and that 'it is more than doubtful if any given species is specially adapted to the exact local conditions in which it is found', other than is necessary from the fact that if not suited to them it will soon die out.

In (17) I devoted more attention to this subject, and suggested as a hypothesis ' that no specific change is too great to appear in one mutation', It was also pointed out that there was no reason to stop at the species, but that it was just as likely that larger units might arise at one step. This position was further elaborated in 'Age and Area', pp. 2I 5-2I.

It will be well to make clear at this point that up to now we have had only two suppositions about the origin of species that have been seriously accepted by the great majority of people, whether biologists or not. These are :

(a) Special Creation: species created showing the differences (commonly large) that actually exist, and that are usually discontinuous.

(b) Natural Selection: species evolved by the gradual selection of small differences between individuals.

Now, as usual, there appear to be portions of the truth in both, and to the latter we owe the enormous advance involved in the acceptance of evolution, an advance which could perhaps have come about in no other way so easily as in one that caught the popular fancy, as did Natural Selection. It is clear that differences between species must arise in one or the other way-gradually or suddenly. But (sudden) creation of them puts a barrier to further investigation, which is obviously unnatural in view of the affinities that exist, and evolution was bound to succeed it. The theory of Natural Selection assumes the accumulation of gradual change, and we have no evidence that such change can be accumulated. What is proposed here, and has been proposed for the last sixteen years, is a compromise between the two views above mentioned. And nothing but some compromise is possible, if one refuse to accept either as a whole, for change must be sudden or gradual, and there is now no possible doubt that evolution (or change) has gone on. There is little or no evidence for the accumulation of variations in one direction, or even for their occurrence except as up-anddown variation in respect of size, \&c. There can be no doubt, after the 
complete failure of the attempts to read adaptive values into the enormous majority of the diagnostic characters of living beings, that there is only rarely any handle for the operation of selection. Personally, I am inclined to think that change was generally effected by a single operation, but every compromise between the extremes is possible. But in view of the work done by Mr. Udny Yule and myself (19), showing that genera in their evolution follow very closely the rule of compound interest, it seems enormously more probable that the changes were single steps.

The current attitude of the Mendelians towards questions of evolution is one of an aggressive agnosticism. Since investigations upon Mendelian lines have not as yet been able to throw as much light upon the problem as had been at one time expected, they seem to think that no other line of attack upon the question will be any more likely to find a way that may possibly lead to something in the nature of a solution of the problem at some future date. They seem inclined to think that because they have not themselves seen a 'large' mutation, such a thing cannot be possible. But such a mutation need only be an event of the most extraordinary rarity to provide the world with all the species that it has ever contained. As I have pointed out ('Age and Area', p. 2I 2), one large and viable mutation upon any area of a few square yards of the surface of the earth, and once in perhaps fifty years, would probably suffice. ${ }^{1}$ The chance of seeing such a mutation occur is practically nil, whilst if the result were subsequently found it would probably be called a relic. Darwin's theory of Natural Selection has never had any proof except from a priori considerations, yet has been universally accepted, and has led to great advances in biology; and until the Mendelians show us how to control mutation (a thing that will evidently be some day possible), the proposition now put forward will presumably go without actual demonstration by verified fact. What I contend is that the facts brought up here and elsewhere go to show that neither of the extreme suppositions-.Special Creation and Natural Selection-contains all the truth, and that therefore this, or some similar, compromise between them is rendered necessary by the present condition of our knowledge.

The small mutations that are all that the Mendelian school will allow are obviously in the highest degree unlikely to give rise to mutual intersterility, such as so commonly characterizes specific difference, and if they were to be accumulated it is difficult to see where the sterility would come in, for each would seem as likely to be fertile with its successor as with its predecessor- $A$ with $B, B$ with $C, C$ with $D$, and so on. But let a big step, say from $A$ to $M$, such as dropping of endosperm, be taken,

${ }^{1}$ Dr. Guppy has suggested that it is by no means uniikely that the many species once seen and never afterwards discoverable may often be such mutations. The case of Christisonia albida, described in Age and Area, p. I $_{5} \mathrm{I}$, is almost certainly a case of a non-viable mutation, and it may be noted that Hooker, who was not a 'splitter', accepted it as a Linnean species. 
and one would feel inclined to expect mutual intersterility as a matter of course.

If so large a difference as having, or not having, endosperm, rumination of endosperm, few or indefinite stamens, \&c., \&c., can occur, as it does occur, over and over again between genera which are obviously closely allied, we are evidently simply making difficulties for ourselves by supposing such differences to be gradually acquired. It must never be forgotten that gradual acquisition is an assumption of the theory of Natural Selection. Whether the differences were infinitesimal (or due to the universally occurring fluctuating variation), or whether they were more of the nature of sports, they were never supposed by Darwin and his followers to be anything but small, and evolution of new species was by their accumulation, whilst the larger groups were due to further accumulation and to destruction of the intermediate forms. Now the work which has been done to establish the theory of Age and Area goes to show that destruction of intermediates can no longer be invoked. There has been vast destruction of individuals, and probably of species which were only represented by a few individuals, but not of intermediates, unless these species which were destroyed were of intermediate type ; and in that case it is difficult to see how they could give rise to the later and more successful forms. Even in the earliest known geological horizons that contain the group there can be recognized many families of flowering plants that exist to-day, and that cover a very large part of the systematic range at present existing. They are as well and as widely separated as those now existing, and into families that now exist, and if these gaps were due to destruction, then Natural Selection must have operated with great rapidity and decision in the earlier ages of the flowering plants. If the earliest known flowering plants already show such differences as that between Monocotyledons and Dicotyledons, then evolution upon the Darwinian plan must have been going on previously (in flowering plants) for an enormously longer period than has since elapsed, or selection and destruction must have been much more rapid.

The view that destruction of intermediate types was chiefly responsible for the differences between families might be more easily upheld were it not for the fact that one may find just as great differences occurring between closely allied genera, or even between species of the same genus, in which cases the time available, upon the Darwinian theory, must have been much less, and much less destruction was possible. Thus, for example, number of stamens is often a character of much importance in classification, yet, to take the first example that comes to hand, Lecythidaceae are marked by $\infty$ stamens, while the next family, Rhizophoraceae, show any number from 8 upwards to $\infty$ (and cf. below). Taking up Mr. Ridley's 'Flora of the Malay Peninsula', it opened at p. 380 , and the first genus noticed was Trigonochlamys, endemic to the region, with two species. T. Griffithii, with 6 stamens, 
occurs from Singapore to Pahang and Perak, or say along 300 miles of the peninsula, while $T$. grandifolia, with 3 stamens (a later and higher type of flower, by current acceptance), occurs upon Bukit Timah, a little hill in Singapore Island. Here was evidently a large mutation, for no destruction can be invoked to fill up a numerical gap like this; and the later-formed species is much more local than the other.

The fact that characters appear in a sporadic way in unexpected places, and in different places in families, is so well known that it has long been an axiom in taxonomic work that the use of single characters to differentiate species, genera, or families will inevitably give an artificial grouping, like the famous sexual system of Linnaeus. Even in this system, it was not practicable to keep the characters intact and still to classify all the species of any genus into that genus. From Lindley ( 7 , pp. xiv, xvii) I take the following interesting remarks about the sexual system :

'Even the sexual system of Linnaeus could not be drawn up without splitting genera, if one desired complete agreement. Smith gives I 73 genera of the British flora, and no less than 43 of these, and some in every class, contain species at variance with the characters of the classes and orders.

'It is a maxim of the Linnean school that the parts of fructification should be employed in characterizing classes, orders, and genera, to the exclusion of all modifications of the leaves or stem. This, although theoretically insisted upon, was practically abandoned by Linnaeus himself, and is to be received with great caution. The organs of fructification are only entitled to a superior degree of consideration when found by experience ${ }^{1}$ to be less liable to variation than those of vegetation.'

We have now to go on to consider very briefly some of the more direct evidence in favour of 'large' mutations. An enormous amount of such evidence is available, thanks to the labours of generations of systematists, botanical and zoological; and it is proposed to give more, if necessary, in future papers.

What principle, if any, has governed the formation of the characters that divide one species, genus, or family from another has long been a great puzzle. The one general rule, which has very many exccptions, seems to be that as one goes higher up the scale from species to family the characters of the vegetative organs tend to be of less and less value as against those of the reproductive organs. This is usually explained as owing to the fact that the latter are less concerned with the performance of the ordinary daily functions of life. But though an everyday statement in teaching, this requires some qualification. In practice one finds that sometimes one, and sometimes another, character runs through a family, and it is only experience, as Lindley says, that can decide what are the most useful characters in any

\footnotetext{
${ }^{1}$ Italics mine.-J. C. W.
} 
given case. If one were to decide that characters of embryo were the most important, and start upon the classification of the Orchidaceae, one would soon be in difficulty. One cannot take single characters, nor can one be sure, till one has actually worked with a family, what characters will prove to be of most importance in that family. Grasses, sedges, palms, duckweeds, aroids, rushes, gingers, bananas, buckwheats, water-lilies, pitcher-plants, sundews, begonias, \&c., \&c., are recognized by their leaves, others by the stem, by leaf-veining, or by other vegetative characters. One may find a character in one place a most important family diagnostic, like rumination of the endosperm, which is the only certain character of distinction between Anonaceae and Magnoliaceae; in another family, as in palms, it may occur over and over again in pairs of closely allied genera, one having it, the other not; whilst in some palms, like Euterpe, it may occur in some species and not in others. Asclepiadaceae can only be divided with certainty from some A pocynaceae by the occurrence of translators to the pollinia-what one would have thought, a priori, a character of trifling importance. There is almost no character of a family or genus that may not at times be generic or specific. So good an account of this fact, which is so well known that people have ceased to think about it, is given by Lindley $(7, \mathrm{p} . \mathrm{xxi})$ that it is worth quoting at some length:

'All Rubiaceae have opposite entire leaves ... but in ... Fuchsia, in which they are usually opposite, species exist in which they are not only alternate, but both one and the other upon the same plant ... in Combretaceae and Leguminosae, orders usually having alternate leaves, they are occasionally opposite . . . in Aceraceae, Aurantiaceae, Geraniaceae, Rutaceae, and Sapindaceae, both simple and compound leaves are found.... Myrtaceae are distinguished by these glands (pellucid dots in the leaves) from Melastomaceae... in ... Phytolaccaceae, Labiatae, \&c., there are, however, genera with and without pellucid dots ... The orders Cistaceae, Saxifragaceae, and Loganiaceae are among the ... cases in which genera exist both with and without stipules.

' The number of sepals is sometimes a character of importance, as in Cruciferae, in which they are always $4 \ldots$ in Malvaceae they are $3-4-5$, in Guttiferae from 2 to 6 ... Malvaceae have the calyx exclusively valvate... but in Penaeaceae both valvate and imbricate aestivation exists . . . it frequently happens that both regular and irregular calices coexist in the same order, as in Rosaceae, Labiatae... in Melastomaceae all degrees of cohesion take place between the calyx and the ovarium, and in Saxifragaceae this uncertainty of structure is still more remarkable.

'If the corolla is present, a plant is said to be dichlamydeous, and much importance is attached to this peculiarity; far more, I think, than it deserves. It constantly separates plants having much natural affinity ... in the polypetalous orders of Crassulaceae, \&c., \&c., there are many monopetalous genera... Compositae are essentially distinguished by their valvate aestivation ... an exception existing in the genus Leptadenia ... Echium in Boraginaceae is irregular. 
'Vitaceae, Gramineae, Cyperaceae ... contain hermaphrodite and diclinous genera and ... flowers of all kinds stand side by side in the Compositae.

'Eschscholtzia has decidedly perigynous stamens, and yet it is ... a genus of Papaveraceae, the character of which is to have them hypogynous; and all kinds of gradations ... are observable in Saxifragaceae ... the stamens are ... monadelphous in Malvaceae... but more commonly this character is unimportant, as in Malvaceae themselves, which have sometimes distinct stamens ... in Solanaceae, the genera of which have usually their anthers bursting longitudinally, the genus Solanum itself opens by pores.

- Cases exist of both forms (apo- and syn-carpous ovary) being found in the same natural order ... in Caryophyllaceae and Bruniaceae there are genera, the ovary of which contains several cells .... in Pedaliaceae and Styraceae both erect and suspended ovules coexist.... the genus Conohoria (Alsodeia) offers .... an instance of three kinds of direction in as many species.

'Marcgraviaceae, Melastomaceae, Myrtaceae, Ranunculaceae, and Rosaceae, \&c. . . . contain both baccate and capsular, dehiscent and indehiscent genera.

'I doubt very much whether presence or absence of albumen deserves much attention in orders ... where the embryo and albumen are of nearly equal bulk ... among Apocynaceae, which have solid albumen, it is ruminate in Alyxia... There are plants among Dicotyledons with only one cotyledon, as Penaea and some Myrtaceae, or several ...'

The diagnostic characters of flowering plants, as regards their classificatory value, are often supposed to rank pretty much in the morphological order, embryo, seed, fruit, gynoecium, androecium, corolla, calyx, inflorescence, bracts, leaves, stem, and root. A glance at the characters that divide Monocotyledons from Dicotyledons is sufficient to show that this is oniy true, if at all, in a very general way, and this impression is soon confirmed if one take up the work of monographing any particular group. Nothing but experience can decide which is the most important character, or the most useful in classifying any family into its genera, \&c. In the Lemnaceae, for example, the genera are divided by characters of the root; in the Cruciferae the hairs, in the Acanthaceae the pollen-patterns, in the Umbelliferae the ridges on the fruit, and the oil-passages in the walls of the fruit, are of the greatest possible importance in defining genera: and so on. The experience must be freshly gained for each family, and the characters that prove by experience, in that family, to be the most widespread and constant, and to differ in the most distinct way between genera that are recognized as such from experience of all their characters, and from continuous distribution, will be the most important in that family. If one were to sort out all characters in terms of the greatest frequency with which they proved to be of importance, one would be quite likely to find that the order above mentioned was adhered to in a general way, but that is all that can be said. 
The essential characters that distinguish one form of specific or higher rank from another are rarely characters of mere size of organs, which might, had they any use-value, vary gradually. More usually they are distinct characters, with no use-value conceivable even in the mature stages, so that it is all but impossible to imagine them going gradually from one to another. As an illustration let us take the characters distinguishing the two Colei often mentioned :

\section{Coleus barbatus \\ ('Bot. Mag.', t. 2318).}

I. Stem cylindrical, tending to quadrangular in inflorescence.

2. Stem pubescent with long hair.

3. Leaves oblong-oval, I-2 in.

4. Leaves closely pubescent.

5. Leaves rather thick.

6. Petioles rather short.

7. Inflorescence of condensed cymes, each about 5 -flowered, forming false whorls of IO flowers at each node.

8. Flowers large.

9. Bracts large.

I0. Calyx with long hairs.

II. Calyx of one large ovate upper tooth and four small lower.

I2. Corolla rich purple or white.

I3. Grows on rocky places.

\section{C. elongatus}

(Trimen's 'Ceylon Flora', t. 74).

Stem quadrangular.

Stem pubescent with short hair.

Leaves ovate-triangular, $\mathrm{I}-2$ in.

Leaves finely pubescent.

Leaves rather thin.

Petioles longer and slenderer.

Inflorescence of one-sided cymes, looking like racemes, about $\mathrm{I} \frac{1}{2}$ in. long, one at each side of each node.

Flowers small.

Bracts small.

Calyx with short hairs.

Calyx of five almost exactly equal teeth.

Corolla pale purple.

Trails over rocks.

Now, looking over these characters, it is at once clear that probably not even an enthusiastic 'splitter' would separate these two forms as more than varieties, if the differences in the characters 7 and II were not present. These differences, however, are so marked that the two plants are almost subgenerically separate. Intermediate stages, with gradual change, are conceivable in the case of characters $\mathrm{I}, 2,3,5,6,8,9$, IO, and I2, but except in the case of 8 and I2, where $C$. barbatus has a larger and more brightly coloured flower, and so might be imagined more attractive to insects, no usevalue can conceivably be put to them. But in the case of the two essential characters 7 and II, not only is there no conceivable use-value, but it is impossible to have intermediate stages, were there even any reason why one should have them. The one could not vary gradually into the other. Nothing but 'large' mutation can explain the difference.

Whatever character one may take, one will find it to be sometimes constant throughout a family, sometimes appearing sporadically in one or more genera, sometimes even only in one or more species of a genus and not in the others. Its value, then, according to circumstances, may be family, 
generic or specific. All this has been so long well known that it has become a truism, which people have accepted as an inexplicable fact, and ceased to think about. And, as in the case of other truisms, it is worth further investigation.

Thus, for example, in many families the fact that the ovary is superior or inferior is a character of the highest value, constant throughout the family, yet in at least 32 families, viz. :

$\begin{array}{llll}\text { Amaryllidaceae } & \text { Cunoniaceae } & \text { Lecythidaceae } & \text { Rhizophoraceae } \\ \text { Anacardiaceae } & \text { Ericaceae } & \text { Liliaceae } & \text { Rosaceae } \\ \text { Araliaceae } & \text { Flacourtiaceae } & \text { Loasaceae } & \text { Rubiaceae } \\ \text { Aristolochiaceae } & \text { Gesneriaceae } & \text { Melastomaceae } & \text { Santalaceae } \\ \text { Bromeliaceae } & \text { Goodeniaceae } & \text { Moraceae } & \text { Saururaceae } \\ \text { Bruniaceae } & \text { Haemodoraceae } & \text { Nymphaeaceae } & \text { Saxifragaceae } \\ \text { Campanulaceae } & \text { Hamamelidaceae } & \text { Pedaliaceae } & \text { Styracaceae } \\ \text { Chloranthaceae } & \text { Lauraceae } & \text { Phytolaccaceae } & \text { Vochysiaceae }\end{array}$

there are exceptions to the rule, plants occurring with inferior ovaries in families that in general have superior, or vice versa. And in a few genera like Saxifraga one may find some species with superior, some with inferior ovary.

It is at once noticeable in this list that these families are in general large families, in which one would be inclined to expect, upon the Darwinian theory, more uniformity with respect to such a character. If it was settled by the early ancestors of A maryllidaceae that an inferior ovary was the best, why did Lophiola in Atlantic North America, and Tribonanthes in South-west Australia, adopt a superior ovary? And one may ask such questions over and over again.

Or take, again, the presence or absence of endosperm, usually considered as one of the most important characters of all. It varies in at least the following 42 families:

$\begin{array}{llll}\text { Acanthaceae } & \text { Flacourtiaceae } & \text { Ochnaceae } & \text { Sterculiaceae } \\ \text { Anacardiaceae } & \text { Gesneriaceae } & \text { Oleaceae } & \text { Tamaricaceae } \\ \text { Apocynaceae } & \text { Gramineae } & \text { Onagraceae } & \text { Thymelaeaceae } \\ \text { Araceae } & \text { Icacinaceae } & \text { Plumbaginaceae } & \text { Tiliaceae } \\ \text { Cactaceae } & \text { Labiatae } & \text { Polygalaceae } & \text { Ulmaceae } \\ \text { Celastraceae } & \text { Leguminosae } & \text { Rhamnaceae } & \text { Urticaceae } \\ \text { Chenopodiaceae } & \text { Loasaceae } & \text { Rhizophoraceae } & \text { Verbenaceae } \\ \text { Connaraceae } & \text { Meliaceae } & \text { Rosaceae } & \text { Violaceae } \\ \text { Crassulaceae } & \text { Menispermaceae } & \text { Rubiaceae } & \text { Zygophyllaceae } \\ \text { Elatinaceae } & \text { Moraceae } & \text { Rutaceae } & \\ \text { Erythroxylaceae } & \text { Nymphaeaceae } & \text { Sapotaceae } & \end{array}$

Again these are, it will be observed, large and well-known families, with few exceptions. And in such genera as Erythroxylum one may find species placed side by side by the most recent taxonomists, one possessing endosperm, the other not. 
But space will not permit of giving long lists of families and genera that illustrate what we have said about the well-known (but little considered) fact that a character may at times be family, at other times only generic or specific. Whether leaves are alternate or opposite is a character that is frequently of great family or generic importance, yet in at least 87 families, and in numerous genera, both may be found. Intermediates are not possible, and neither arrangement has any use-value as against the other.

When the character is of great systematic importance it has in general no conceivable use-value as, against the contrasted character, and cannot have been the subject of Natural Selection. It is impossible to conceive that it can matter in the struggle for existence whether the corolla is valvate or imbricate, the leaves alternate or opposite, the endosperm ruminate or equable, and so on, or whether, to take even more widespread characters, the embryo is mono- or di-cotyledonous, or the leaves net- or parallel-veined. As Guppy says ('Age and Area', p. I02), the Darwinian theory 'implies that the simpler, least mutable, and least adaptive characters that distinguish the great families are the last developed. This could never have been.' Further than this, they are not capable of change from one to the other, whether by gradual variation or by destruction of intermediates, or both. One cannot conceive of alternate leaves becoming gradually opposite, nor in fact does one find any fossil relics showing intermediate stages. The same may be said of the various aestivations of the corolla, of trimery, of porous opening of anthers, number and arrangement of the ovules, \&c., \&c. It is impossible to conceive, as I have maintained for twenty years, that Natural Selection can have produced such characters, and to argue that they are correlated with important characters due to Natural Selection is simply to invoke incomprehensibility, as did the special creationists. These latter characters cannot be external, or they would have been noticed and utilized by the taxonomists, and to argue that they are all internal is to ask too much of credulity; nor does it get over the chemical difficulty which was pointed out so long ago as 1877 (p. $6 \mathrm{c} 6$ ). If internal characters proceed by gradual selection, why does their external manifestation go in jumps, as must of necessity be the case with many of the most important characters? What intermediate types are conceivable between porous, valvular, longitudinal, and transverse opening of anthers-all at times family characters?

Or take 'smaller' variations, i. e. variations which we do not know to be in reality any smaller, but variations which experience has proved to be only available as specific or generic. In Abrus (Leguminosae, PapilionataeVicieae), in Adenanthera (do. Mimosoideae-Adenanthereae), in Ormosia (do. Papilionatae-Sophoreae), and in Rhynchosia (do. Papilionatae-Phaseoleae) some of the species have seeds which are sharply divided into a red end and a black end by a difference in the colour of the testa, which is 
vividly red at one end and as vividly black at the other, the division following a perfectly straight line across the seed. Other species have simple bright red seeds. Incidentally, this is as good a case of 'mimicry' as those described in animals, and was at one time seriously advanced as such. No use-value can be suggested, and no intermediates are possible, nor is it conceivable that Natural Selection would work to such minuteness of detail as to divide the two colours by an exact straight line in all cases. There is nothing for it but to admit that it must have been acquired at one step. And the same step must have been taken by several different plants, for the four genera do not belong to the same division of Leguminosae, and one of them does not even belong to the Papilionatae.

We may proceed by giving one instance in some detail of the way in which a character that in one place is of family rank may in another become merely generic or specific. Whether the endosperm is or is not ruminate is the only general character of distinction between Anonaceae and Magnoliaceae, yet in Alyxia (Apocynaceae), in Aralidium and other genera (Araliaceae), in Polysphaeria (Rubiaceae), in Tinospora and others (Menispermaceae) rumination appears as merely a generic character, whilst in the palms, to give full details, it appears in the left-hand genus of each of the following pairs of genera that are placed side by side in the classification (numbers from Drude's classification in 'Die naturlichen Pflanzenfamilien', i 889$)$ :

\section{Ruminate.}

2. Chamaerops (sub-fam. I. 2)

20. Copernicia (I. 2)

23. Medemia (II. I)

30. Raphia (III. 2)

42. Caryota (IV. I a)

58. Catoblastus (IV. I c)

69. Reinhardtia (IV. Id)

73. Prestoea (IV. I e)

78. Iguamura (do.)

82. Heterospathe (do.)

87. Phoenicophorium (do.)

90. Oncosperma (do.)

93. Ptychandra (do.)

101. Ptychococcus (do.)

109. Nenga, p.p. (do.)
Not ruminate.

3. Trachycarpus

19. Serenaea

24. Hyphaene

31. Oncocalamus

43. Arenga

57. Iriartea

68. Synechanthus

72. Hyospathe

77. Linospadix

81. Clinostigma

88. Deckenia

89. Acanthophoenix

94. Cyphokentia

100. Cyrtostachys

i Io. Cyphophoenix

It is impossible to escape the conclusion that all or most of these fifteen genera on the left must have acquired rumination independently. They belong to nearly every group of palms, and agree closely in other characters, each with the one opposite to it. If we suppose them to have descended from a pair of ancestors that agreed to separate on the question of endosperm, we must explain why they also disagree in other characters of 
great importance, such as the number of the stamens, which varies from six to a very large number. Rumination has no use-value as against nonrumination, and there are no intermediates conceivable that would have any value. Either the same character has been acquired over and over again, or genera are not units of descent, but are polyphyletic, as has often been suggested (cf. 11, p. 446; 20; or 1, p. I 19). ${ }^{1} \quad$ This latter supposition, however, does not seem to cover more than a very small proportion of the cases, and we are driven to the conclusion that the same indifferent, but systematically very important, character, which rarely admits of intermediate stages, and which therefore cannot have been acquired gradually or by selection, has been acquired over and over again. Nothing but sudden acquisition, or in other words ' large' mutation, seems capable of explaining this phenomenon, which is familiar to every worker in taxonomy.

But the acquisition of ruminate endosperm is not even a question of acquisition by one genus only and not by another. In the four following palms part of the genus shows it and part does not, so that it becomes merely a specific character, and it is clear that one species may acquire it and another not :

$\quad$ Ruminate.
Euterpe oleracea
Oenocarpus, \& II
Hydriastele, p.p.
Nenga, \$\& I, II, III

Non-ruminate. Euterpe, other spp. Oenocarpus, § III Hydriastele, p.p. Nenga, \&\& IV, V

Or one may take evidence of a different kind by taking a single family and considering its range of variation. Take for example the Rubiaceae. None of the important characters of the family run unchanged throughout it, and one finds, for instance (the contrasted character is the usual one in the family) :
alternate leaves in Didymochlamys;
whorled leaves in Fadogia;
pinnate leaves in Pentagonia;
gland-dotted leaves in Rustia;
intrapetiolar stipules in many;
leafy stipules in Galieae ;
dioecious flowers in Kotchubaea;
zygomorphic flowers in Capirona ;
solitary axillary flowers in many;
male and female inflorescences often very different ;
male and female flowers so different in Melanopsidium that they were formerly described as different genera ;
flowers united in pairs in Morinda, \&c.
male flower 4-5-merous, female 8-merous, in Thieleodoxa;

1 Sir N. Yermoloff (20), in his studies of the Diatomaceous genus Navicula, appeals to a principle of integration rather than to the differentiation of types, i. e. to the building up rather than to the breaking down of types. 
Gradual, Change, and by Guppy's Method of Differentiation. 625

calyx large and convolute in Dictyandra, large and imbricate in Keenania, breaking open irregularly in Pelagodendron, with calyculus in Retiniphyllum, with one large sepal in Mussaenda, \&c., 5-merous in $\Varangle$ and 2 -merous in $q$ in Phyllis; aestivation descending in corolla of Posoqueria and Molopanthera; stamens united in Capirona, Bikkia, Chiococcus, unequal in Hippotis, 8-12 in Praravinia, opening by pores in Rustia, by valves in Tresanthera, two, with 5-merous corolla in Sylvianthus, \&c.; anther multilocular in Dictyandra, with poliinia in Randia acuminata; stamens often long and short (heterostyly); ovary superior in Gaertnera, and in spp. of Oldenlandia ; ovaries united in pairs in Morinda;

ovary I-locular in Acranthera, Casasia, \&c., 3-5-locular in Cuviera, \&c. 4-locular in Euosmia, 6-1o-locular in Praravinia, $\infty$-locular in Timonius;

stigma Io-lobed in Mesoptera;

capsule septicidal for loculicidal; schizocarp in Diodia, Richardsonia, Xanthophyllum, \&c.; several with circumscissile capsule ; some with berry ;

no endosperm in Abbottia, Guettarda, \&c.; ruminate endosperm in Polysphaeria;

radicle of embryo sometimes curved; no cotyledons in embryo of Guettarda.

There is no escape from the conclusion that characters of all kinds, however important they may be in classification, may be acquired over and over again by single genera, and therefore that they can be easily acquired without needing an immense period for the acquisition.

It is also very striking that characters are more constant in small families than in large. This of course is well known, and I shall doubtless be accused of talking platitudes in bringing forward such a point. But it is not what one would expect upon the Darwinian theory. If the common ancestor of the Rubiaceae had the characters that are most widespread throughout the family, such as opposite leaves, regular flowers, free stamens, inferior ovary, capsule, endosperm, straight embryo with cotyledons, \&c., why are members of the family found that depart from all these characters, when this is a large and 'successful' family, that presumably owes its success to its characters? These 'abnormal' characters do not occur in the most nearly related families to the Rubiaceae, so that to imagine them as survivors when the Rubiaceae were isolated from others by destruction of the intermediates, will not help the matter. If they connect the Rubiaceae to any families, it is not to the families usually regarded as their allies, such as Caprifoliaceae. Further, why do the small families, so often supposed to be relics, show such constancy? One would incline to expect more variety in them.

In what has been said so far I have left entirely out of consideration what seems to me the greatest proof of all for the probability that evolution 
has taken place by sudden mutations covering the whole gap between forms. This is the work of Mr. G. Udny Yule and myself upon the statistics of evolution. In that paper (19) we have shown that the evolution of new genera out of old follows with quite astonishing exactness the rule of compound interest. The close approximation of the logarithm curves to straight lines (an exact straight line would mean an exact following of the law of compound interest) leaves no room for doubt that this is the rule which evolution has followed. After a given time one genus has become two, and after another period of time two have become four, and so on. Now if genera and species are formed upon such a rule, it would seem all but inconceivable that they should have been formed by gradual steps, or in any other way than by sudden change. Not only does this appear, but it is also clear that the large genera must be the ancestors of the small; the genera cannot have arisen from common parents, now extinct, as is demanded by the Darwinian theory. The general result of the work is to show that evolution has proceeded upon a very definite plan; ' the manner in which it has unfolded itself has been relatively little affected by the various vital and other factors, these only causing deviations this way and that from the dominant plan.' If one accept the idea of gradual development of species and genera, in view of this work, then one must suppose that all the stages in that gradual development proceeded upon definite preordained lines.

In later papers the thesis which has been briefly indicated here will be worked out with greater profusion of illustration. The object now is simply to show that the evolution of species from one another by means of large mutations is a highly probable occurrence. One species may thus be the parent-direct or indirect-of a number of others, found upon the same area, or upon portions of it, as both Guppy and myself have shown with regard to local endemics. That variation consequently has a tendency to be centrifugal is thus rendered extremely probable, and this question will be dealt with later in more detail.

\section{SUMMARY.}

This paper attempts to set forth some of the arguments in favour of the origin of species by large mutations, rather than by the gradual accumulation of small variation (whether infinitesimal or mutational) that is assumed in the Darwinian theory, and for which no proof whatever has yet been given. Some compromise between the two extreme suppositions-Special Creation, by which species were created with the existing large differences, and Natural Selection, by which they were evolved by accumulation of small differences-is needful, and it is suggested that the best is the evolution of 


\section{Gradual, Change, and by Guppy's Method of Differentiation. 627}

species by ' large' differences that suddenly appear. Neither of the extremes can now command general acceptance, and it is suggested that they should, so to speak, exchange partners.

Natural Selection is essentially a theory of progressive adaptation, and it is shown that adaptation usually involves correlation, and there is no reason to suppose that gradual stages, always correlated, can be picked out, whilst often the one half of the selection could not be made till the other half was complete, and the result of the latter only would be fatal, as in tropical lianas, for example, where the twining stem could not begin to be selected till the weak and flexible stem had been produced, though the latter, with no means of support, would be at a hopeless disadvantage.

A brief account is given of my former investigations of the endemic species of Ritigala, and it is shown that the chief distinguishing characters of Coleus elongatus (to take a definite example) do not allow of intermediate forms, nor can they be the subject of Natural Selection. The only reasonable explanation is that they were formed by large changes. And the same is the case for a vast proportion of important distinguishing characters between species generally.

Guppy's Differentiation theory, which is upon much the same lines, is then touched upon, with some notes by Dr. Guppy himself.

Other published work is then described in brief, all pointing to the same general conclusion, and it is shown that destruction of intermediates, usually called in upon the Darwinian theory, will not explain the facts, nor, in the majority of cases, is there any reason for it.

It is then pointed out that nothing but experience can decide what are the most useful distinguishing characters in any given case. To make up one's mind beforehand to use chiefly characters $A, B$, and $C$, for example, would only be to court disaster.

Instances are given of characters sometimes of great importance as family diagnostics and in other cases only generic or specific ; and the characters of the 'abnormal' members of Rubiaceae are given in full detail to show how in a single large family no character whatever need necessarily be steadfast throughout the family. The incidence of rumination of endosperm, sometimes (e.g. in the palms) a generic or even only a specific character, is described in more detail, but such detailed work must in general be left for later papers.

Finally, the very conclusive evidence in favour of large mutations that is given by the work of Mr. Yule and the author is touched upon. If genera follow in their evolution the rules of compound interest, then it is practically impossible to suppose them formed in any other way than by sudden mutations. All the evidence that is produced in this paper points to the same conclusion. 


\section{LITERATURE CITED.}

1. Bower, F. O. (1918): Natural Classification of Plants (Hooker Lecture). Journ. Linn. Soc., xliv, I918, p. I07. Cf. especially p. II9.

2. Coe, C. C. : Nature versus Natural Selection, London, 1895 .

3. DE VRies, H. (1910): The Mutation Theory. Engl. trans. London, i9io.

4. Guppy, H. B. (1906): A Naturalist in the Pacific, vol. ii. London, I906.

5. - (1917) : Plants, Seeds, and Currents in the West Indies and Azores. Ibid., I917.

6. Hooker, J. D. (1853): Botany of the Voyage... Erebus and Terror. Vol. ii, Flora of New Zealand. London, 1853 .

7. Lindley, J. (1830): Introduction to the Natural System of Botany. London, 1830.

8. Lyell, C. (1853) : Principles of Geology, 9 th ed. London, 1853 .

9. Maclaren, J. J. (1877): Some Chemical Difficulties of Evolution. London, i877.

10. Willis, J. C. (1897) : Dictionary of Flowering Plants and Ferns, 2nd ed. Cambridge, I904;

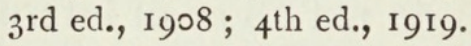

11. - (1902): Studies of ... Podostemaceae. Ann. R. B. G. Perad., i, 1902, p. 267.

12. (1906): The Flora of Ritigala. Ibid., iii, I906, p. 27 I.

13. — (1907): Some Evidence against ... Natural Selection ... Ibid., iv, I907, p. I.

14. - (1907): Further Evidence against ... Natural Selection ... Ibid., p. I 7.

15. - (1907): Geographical Distribution of the Dilleniaceae. Ibid., p. 69.

16. (1907): The Floras of Hill-tops in Ceylon. Ibid., p. I3 I.

17. - (1915): The Endemic Flora of Ceylon. Phil. Trans., B., ccvi, 1915, p. $3^{6} 7$, and correction in Proc. Roy. Soc., Bot., lxxxiv, I9I6.

18. (1922): Age and Area. Cambridge, I922.

19. - and Yule, G. U. (1922) : Some Statistics of Evolution and Geographical Distribution in Plants and Animals, and their Significance. Nature, 109, Feb. 9, I922, p. I77.

20. Yermoloff, N. (1922-3): On Navicula. Proc. Linn. Soc., 1922-3. 


\section{$2 \mathrm{BHL}$ Biodiversity Heritage Library}

Willis, J. C. 1923. "The origin of species by large, rather than by gradual, change, and by guppy's method of differentiation." Annals of botany 37, 605-628. https://doi.org/10.1093/oxfordjournals.aob.a089870.

View This Item Online: https://www.biodiversitylibrary.org/item/270686

DOI: https://doi.org/10.1093/oxfordjournals.aob.a089870

Permalink: https://www.biodiversitylibrary.org/partpdf/319106

\section{Holding Institution}

New York Botanical Garden, LuEsther T. Mertz Library

\section{Sponsored by}

BHL-SIL-FEDLINK

\section{Copyright \& Reuse}

Copyright Status: Public domain. The BHL considers that this work is no longer under copyright protection.

This document was created from content at the Biodiversity Heritage Library, the world's largest open access digital library for biodiversity literature and archives. Visit BHL at https://www.biodiversitylibrary.org. 